\title{
800 años de la Carta Magna Inglesa: Su proyección en el derecho constitucional chileno
}

El 15 de junio de este año se celebraron los 800 años de la Carta Magna de Juan Sin Tierra. En sus breves, pero notables disposiciones se condensan los primeros antecedentes del Derecho Constitucional, en particular, de las libertades fundamentales de los ciudadanos y de las garantías frente a los abusos del poder por parte de la autoridad.

\section{Antecedentes}

Juan I, quien no recibió dominios de su padre Enrique II de Inglaterra, a la vez que prácticamente no consiguió territorios a su nombre, lo que motivó su "apodo" de "Juan Sin Tierra", comenzó a gobernar a partir de 1199, como consecuencia del fallecimiento de sus hermanos (Enrique y Godofredo) y por la sucesión de su otro hermano Ricardo “corazón de león”.

Tal como señalan los historiadores y especialistas, dicho monarca se enfrentó a tres grandes poderes: el Rey de Francia (Felipe Augusto, quien lo derrotó en Bouvines, en 1214), la Iglesia Católica (como consecuencia del conflicto por la sucesión en el Arzobispado de Canterbury, en tiempos del Papa Inocencio III, quien llegó incluso a decretar su excomunión) y los Barones ingleses (los que rechazaban el aumento de las exacciones reales que principalmente financiaban las campañas contra Francia, todo lo cual incluso llevó a frustradas conspiraciones contra el rey).

Por ello, como resalta Alberto Bianchi, tal como por lo demás ha ocurrido con la gran mayoría de los estatutos constitucionales, "la Carta Magna no fue el fruto de la generosidad de un gobernante deseoso de reconocer o ampliar las libertades de sus súbditos. Muy por el contrario, fue el resultado del desastroso y arbitrario gobierno de un Rey que, vencido por sus enemigos externos y excomulgado por el Papa, se vio forzado por sus barones a firmar un documento el cual consideraba una bumillación a su poder y que, naturalmente, no tenía intención alguna de cumplir o poner en práctica" ("Historia de la formación constitucional del Reino Unido", Editorial Cathedra Jurídica, Buenos Aires, 2009). 
El acto de suscripción de la Carta Magna se efectuó en una muy breve ceremonia en la colina de Runnymede, entre Windsor y Staines, junto al río Támesis.

\section{Contenido}

Dicho documento, que consta de 63 artículos, estaba escrito en latín, sobre pergamino, incluyendo el sello real.

\section{Derechos y libertades}

En materia eclesiástica, se precisa que "la Iglesia de Inglaterra será libre y gozará inviolablemente de todos sus derechos y libertades" (I)

Del mismo modo, dicho documento reconoce una serie de derechos hereditarios de los nobles (II a VI) como de sus viudas (VII y VIII).

Por su parte, el monarca se compromete a no "embargar tierra o renta por ninguna deuda, mientras haya muebles del deudor en la finca, que sean bastante para pagar la deuda" (IX). De igual forma, se alude a ciertas disposiciones respecto de deudas y su forma de pago por la viuda y sucesión (X y XI). Se contienen adicionalmente ciertas prescripciones sobre indemnización de las expropiaciones, debiendo pagarse al contado (XXVIII a XXXI).

Se establece también que "la ciudad de Londres gozará de todas sus libertades antiguas y franquicias tanto por tierra como por mar" como igualmente "que las demás ciudades, burgos poblaciones y puertos gocen de todas sus libertades y franquicias"(XIII). Igualmente, se alude a la libre circulación de las mercaderías, de modo que todo comerciante pueda "salir salvos y seguros de Inglaterra y volver a ella, y permanecer alli, y pasar tanto por agua como por tierra a comprar y vender, según las costumbres antiguas y permitidas, sin ningún perjudicial portazgo"(XLI); como a la libre entrada y salida del territorio, siendo "legal para cualquiera irse fuera del reino y volver a él salva y seguramente por tierra o por agua" (XLII).

\section{Legalidad de los tributos}

Pero sin duda que una de las disposiciones que más suele citarse es la normativa sobre "scutage", correspondiente a un tributo pagado por los nobles en lugar de prestar auxilio militar. Al efecto, se prescribe por la Carta Magna que "no se impondrá derecho de escudo de nuestro reino, a menos que sea por el Consejo General de nuestro Reino, excepto para redimir nuestra persona, y para armar caballero a nuestro hijo mayor, y para casar una vez nuestra hija mayor; y para esto se pagará un subsidio razonable. De la misma manera deberá ser respecto de los subsidios de la ciudad de Londres" (XII). Para obtener el consentimiento se obliga a "convocar individualmente y por carta a los arzobispos, obispos, abades, duques y barones principales”(XIV). Del mismo modo, se 
resalta que en el futuro "nadie exigirá 'ayuda' a algunos de sus vasallos libres salvo para rescatar su propia persona, para armar caballero a su hijo primogénito y para casar (una vez) a su hija mayor" y con estos fines "únicamente se podrá imponer una ayuda razonable" (XV)

\section{Debido Proceso}

Ciertamente que uno de los principales aspectos que marcan su legado son aquellos correspondientes a los principios de un justo y racional proceso.

Así, pueden citarse, entre otros, las siguientes garantías: a) que los litigios se celebrarán en lugares fijos, esto es, "en un lugar cierto" (XVII), obligándose el rey a enviar a funcionarios judiciales a cada condado (XVIII); b) que las multas deben ajustarse al principio de proporcionalidad, de manera que "por simple falta un hombre libre será multado únicamente en proporción a la gravedad de la infracción y de modo proporcionado por infracciones mas graves, pero no de modo tan gravoso que se le prive de su medio de subsistencia", debiendo siempre las multas imponerse por "el juramento de hombres buenos del vecindario" (XX); c) que como consecuencia de lo anterior, "los condes y barones serán multados únicamente por sus pares y en proporción a la gravedad del delito" (XXI); y d) que los funcionarios administrativos de la Corona (sheriff, constable o coroner) no podrán tener pleitos de la Corona (XIV).

De igual manera, deben destacarse los siguientes principios procesales: a) la necesidad de presentar testigos de cargo, de modo que nadie pueda ser arrastrado a juicio "en virtud únicamente de acusaciones suyas, sin presentar al mis o tiempo a testigos directos dignos de crédito" (XVIII); b) derecho a un juicio debido, de forma tal que "ningún hombre libre podrá ser detenido o encarcelado o privado de sus derechos o de sus bienes, ni menos fuera de la ley ni desterrado o privado de su rango de cualquier otra forma" sino "en virtud de sentencia judicial de sus pares o por ley del reino" (XXXIX); c) la justicia de la decisión, de modo que "no venderemos, denegaremos ni retrasaremos a nadie su derecho ni la justicia" (XL); d) la sujeción a la ley, razón por la cual "no nombraremos jueces, ni comisarios, ni alguaciles o sheriffs, sino los que conozcan las leyes del reino y están dispuestos a observarlas" (XLV); e) que "si alguno, sin previo juicio legal de sus pares, ha sido desposeido o privado de sus tierras, castillos, libertades o derechos, se los restituiremos inmediatamente" (LII); y f) que los procesos deben ser gratuitos, de suerte que "no se dará ni tomará nada por un auto de investigación del que desea que tal investigación se haga respecto de vida o miembro, sino que se decretará gratis" (XXXVI).

\section{Otras disposiciones}

Del mismo modo, se incluyen disposiciones sobre pesos y medidas (XXXV), bosques (XLIV, XLVII y XLVIII).

Por último, se preceptúa que un cuerpo colegiado, integrado por 25 barones, estará encargado de velar por el fiel cumplimiento de la Carta Magna, de modo que "cuidarán todo su poder de poseer y observar, y hacer que se observen la paz y libertades que les hemos concedido, y que confirmamos por nuestra presente Carta" (LXI) 


\section{Origen de las garantías tributarias y procesales.}

Las garantías de la legalidad de los tributos y los principios de un justo y racional proceso encuentran -como se aprecia- su antecedente en la Carta Magna, lo que tiene influencia hasta nuestros días, incluso en nuestro sistema constitucional.

\section{Legalidad de los tributos}

En efecto, tal como se expresó y lo ha recordado nuestro Tribunal Constitucional, el principio de legalidad en materia tributaria tiene sus antecedentes remotos en Occidente en la Carta Magna de 1215, en su célebre artículo 12, conforme al cual 'no se podrá exigir 'fonsadera' ('scutage') ni 'auxilio' (aid) en nuestro Reino sin el consentimiento general". Luego, en el Petition of Right, de 1628, se reitera que nadie está obligado "apagar impuesto o tasa alguna, salvo común consentimiento otorgado por Ley del Parlamento" (artículo 10). A su vez, en el Bill of Rights, de 1689, se reitera que es ilegal el cobro de impuestos "sin consentimiento del Parlamento" (artículo IV).

En el derecho comparado, como se ha indicado, el principio de legalidad tributaria ha sido ampliamente reconocido desde sus orígenes en el mundo anglosajón.

Así, la Constitución de Estados Unidos, en su artículo $1^{\circ}$, sección primera, establece que "todo proyecto de ley para imponer tributos se presenta en la Cámara de Representantes", correspondiéndole al Congreso el imponer y recaudar contribuciones.

En la Europa Continental también ha tenido amplio desarrollo.

En Italia, por ejemplo, se establece que "no sepodrá imponer prestación personal o patrimonial sino en virtud de lo dispuesto en la ley" (artículo 23).

Por su parte, el artículo 105 de la Carta Fundamental de Alemania otorga potestad legislativa exclusiva a la Federación en materia de aduanas y monopolios fiscales y concurrente sobre los demás impuestos.

A su vez, la Constitución española indica que "la potestad originaria para establecer tributos corresponde exclusivamente al Estado mediante ley” (artículo 113).

La Constitución francesa también se encarga de entregar a la reserva legislativa lo referente a "la base, tipo y modalidades de la recaudación de impuestos de toda clase" (artículo 34). En este último caso, ello se vincula -por lo demás- con la Declaración de Derechos del Hombre y del Ciudadano, según la cual "todos los ciudadanos tienen el derecho de comprobar, por si mismos o por sus representantes, la necesidad de la contribución pública, de aprobarla libremente, de vigilar su empleo y de determinar su tipo, su base, su recaudación y su duración" (artículo 14).

En nuestro país la legalidad tributaria se consagra a partir de la Constitución de 1812.

La Carta de 1833 aseguraba a todos los habitantes de la República que sólo en virtud de una ley se podía "imponer contribuciones de cualquier clase o naturaleza, suprimir las existentes y determinar en caso necesario su repartimiento entre las provincias y departamentos" (artículo $37 \mathrm{~N}^{\circ} 1$ ). 
A su vez, la Constitución de 1925 reconocía "la igual repartición de los impuestos y contribuciones, en proporción de los haberes o en la progresión oforma que fije la ley" (artículo $10 \mathrm{~N}^{\circ}$ 9), reiterando que era reserva del legislador el "imponer contribuciones de cualquier clase o naturaleza, suprimir las existentes, señalar en caso necesario su repartimiento entre las provincias o comunas, y determinar su proporcionalidad oprogresión" (artículo 44 No 1 )".

La actual Carta Fundamental, en su artículo 19 №20, establece como garantía "La igual protección de los tributos en proporción a las rentas o en la progresión o forma que fije la ley; y la igual repartición de las demás cargas públicas" y, adicionalmente, que "En ningún caso la ley podrá establecer tributos manifiestamente desproporcionados o injustos". Dichos tributos son de iniciativa exclusiva del Presidente de la República (artículo 65, N¹) y su discusión sólo puede tener su origen en la Cámara de Diputados (artículo 65, inciso $2^{\circ}$ ).

En relación al alcance de esta garantía, nuestro Tribunal Constitucional nos ha recordado que " $e l$ principio de legalidad en materia tributaria tiene sus antecedentes remotos en Occidente en la Carta Magna de 1215, en su célebre articulo 12", de forma tal que "de acuerdo a sus orígenes históricos, se encuentra fuertemente vinculado al principio de la soberanía nacional", razón por la cual "el Congreso Nacional debe ser, por tanto, el lugar en el que los ciudadanos discutan e impongan libremente las cargas públicas patrimoniales, entre ellas, ciertamente, los tributos", debiendo dicha ley, emanada del Congreso Nacional, "indicar con suficiente precisión todos los elementos esenciales de la obligación tributaria, esto es, el sujeto pasivo obligado, el hecho gravado, la base imponible, la tasa imponible y las situaciones de exención"(Roles 718,759 y 773 , de 2007).

\section{Debido Proceso}

De acuerdo a la Quinta Enmienda de la Constitución de Estados Unidos, heredera de la Carta Magna, "Nadie estará obligado a responder de un delito castigado con la pena capital o con otra infamante si un gran jurado no lo denuncia o acusa, a excepción de los casos que se presenten en las fuerzas de mar o tierra o en la milicia nacional cuando se encuentre en servicio efectivo en tiempo de guerra o peligro público; tampoco se pondrá a persona alguna dos veces en peligro de perder la vida o algún miembro con motivo del mismo delito; ni se le forzará a declarar contra símisma en ningún juicio criminal; ni se le privará de la vida, la libertad o la propiedad sin el debido proceso legal; ni se ocupará su propiedad privada para uso público sin una justa indemnización". Por su parte, la Sexta Enmienda reconoce el derecho a un juicio justo en los siguientes términos: "En todas las causas penales, el acusado disfrutará del derecho a un juicio público y expedito a cargo de un jurado imparcial del Estado y distrito donde el delito hay a sido cometido; tal distrito previamente habrá sido determinado conforme a la ley y dicho acusado será informado de la indole y el motivo de la acusación; será confrontado con los testigos que se presenten en su contra; tendrá la obligación de obtener testimonios a su favor, y contará con la asistencia jurídica apropiada para su defensa".

Por su lado, el artículo 10 de la Declaración Universal de los Derechos Humanos señala que "toda persona tiene derecho, en condiciones de plena igualdad, a ser oida públicamente y con justicia por un tri- 
bunal independiente e imparcial, para la determinación de sus derechos y obligaciones o para el examen de cualquier acusación contra ella en materia penal".

A su vez, el Pacto Internacional de Derechos Civiles y Políticos, publicado en el Diario Oficial el 29 de abril de 1989, reconoce en su artículo 14 a toda persona el "derecho a ser oída públicamente y con las debidas garantias por un Tribunal competente, independiente e imparcial, establecido por la Ley, en la substanciación de cualquier acusación de carácter penal formulada contra ella o para la determinación de sus derechos u obligaciones de carácter civil". Del mismo modo, se indica que en principio "toda sentencia en materia penal o contenciosa será pública”.

A lo que debe agregarse, la Convención Americana sobre Derechos Humanos, publicada en el Diario Oficial de 5 de enero de 1991, que en su artículo 8 también cautela el "derecho a ser oído, con las debidas garantias y dentro de un plazo razonable, por un juez o tribunal competente, independiente e imparcial, establecido con anterioridad por la ley, en la sustanciación de cualquier acusación penal formulada contra ella, o para la determinación de sus derechos y obligaciones de orden civil, laboral, fiscal o de cualquier otro carácter".

En Europa, específicamente, en la Constitución española se encuentra lo atingente al debido proceso en su artículo 24 el que prescribe: "1. Todas las personas tiene derecho a obtener la tutela judicial efectiva de los jueces y tribunales en el ejercicio de sus derechos e intereses legitimos, sin que, en ningún caso, pueda producirse indefensión. 2. Asimismo, todos tienen derecho al Juez ordinario predeterminado por la ley, a la defensa y a la asistencia de letrado, a ser informados de la acusación formulada contra ellos, a un proceso público sin dilaciones indebidas y con todas las garantias, a utilizar los medios de prueba pertinentes para su defensa, a no declarar contra si mismos, a no confesarse culpables y a la presunción de inocencia. La ley regulará los casos en que, por razón de parentesco o de secreto profesional, no se estará obligado a declarar sobre hechos presuntamente delictivos."

En Alemania, si bien la doctrina estudia el debido proceso a partir de diversos preceptos constitucionales, la Ley Fundamental alemana contiene disposiciones que aluden a este derecho, a saber: a) "Toda persona cuyos derechos sean vulnerados por el poderpúblico, podrá recurrir a la vía judicial. Si no hubiese otra jurisdicción competente para conocer el recurso, la vía será la de los tribunales ordinarios."(artículo 19.4.); b) "No están permitidos los tribunales de excepción. Nadiepodrá ser sustraido a su juez legal."(artículo 101.1); y c) "Todos tienen el derecho de ser oídos ante los tribunales" (artículo 103.1).

En Italia, al respecto, se encuentran diversas normas fundamentales relativas a las garantías que componen el debido proceso, tales como a) el derecho de las personas a "acudir a los tribunales para la defensa de sus derechos y de sus intereses legítimos" (artículo 24 inciso $1^{\circ}$ ); b) el derecho a la defensa "en todas las etapas del procedimiento" (artículo 24 inciso $2^{\circ}$ ) y a los que carecen de recursos económicos (artículo 24 inciso $3^{\circ}$ ); c) el derecho al juez natural (artículo 25); el derecho a una decisión judicial motivada (artículo 111); el derecho a impugnar lo resuelto, especialmente a una casación por infracción de ley (artículo 111, inciso $2^{\circ}$ ); y el derecho a impugnar los actos de la administración (artículo 113).

Cabe por último recordar que el Tratado europeo de derechos humanos, en su artículo $6^{\circ}$, preceptúa que "toda persona tiene derecho a que su causa sea oída equitativa, públicamente y dentro de un plazo razonable, por un tribunal independiente e imparcial, establecido por la ley, que decidirá los litigios sobre sus derechos y obligaciones de carácter civil o sobre el fundamento de cualquier acusación en materia penal 
dirigida contra ella". A su vez, la misma normativa indica que los acusados tienen como derechos mínimos el ser informado de la acusación, disponer de tiempo y facilidades para la preparación de la defensa, ser asistido por un defensor, interrogar a los testigos y ser asistido gratuitamente por un intérprete. Finalmente, el artículo 13 asegura el derecho a un recurso efectivo, en términos tales que "toda persona cuyos derechos y libertades reconocidos en el presente convenio hayan sido violados tiene derecho a la concesión de un recurso efectivo ante una instancia nacional, incluso cuando la violación haya sido cometida por personas que actúen en el ejercicio de sus funciones judiciales".

En nuestro país, curiosamente las primeras Constituciones contemplaban ciertas referencias a los elementos de un debido proceso, mientras que las posteriores se limitaron más bien al establecimiento de garantías en el ámbito penal y libertad de movimiento. En efecto, el Reglamento Constitucional de 1812 indicaba que "ninguno será penado sin proceso y sentencia conforme a ley" (artículo 18). A su vez, la Constitución Política de 1818 establecía que nadie "debe ser castigado o desterrado, sin que sea oído y legalmente convencido de algún delito contra el cuerpo social”. (artículo 2). Por su lado, la Carta de 1822 preceptuaba que "toda sentencia civil y criminal deberá ser motivada". (artículo 219) La Constitución moralista de Egaña, de 1823, aseguraba el derecho a la primera instancia y a una apelación (artículo 137). Mientras que la Carta liberal de 1828 reconocía la jurisdicción sólo respecto de ataques a la sociedad o perjuicio a terceros. (artículo 12).

La Constitución de 1833, en una disposición que reitera la de 1925, señalaba que "ninguno puede ser condenado, si no es juzgado legalmente, y en virtud de una ley promulgada antes del hecho sobre que recae el juicio" (artículo 133).

El actual artículo $19 \mathrm{~N}^{\circ} 3$ inciso $5^{\circ}$ de la Constitución Política de la República, siguiendo también la tradición anglosajona, establece que "toda sentencia de un órgano que ejerza jurisdicción debe fundarse en un proceso previo legalmente tramitado. Corresponderá al legislador establecer siempre las garantías de un procedimiento y una investigación racionales y justos".

El Tribunal Constitucional ha recordado en diversas sentencias que "los elementos que conforman lo que en la tradición anglosajona se ha denominado "due process of law", esto es, el debido proceso legal, y que se remonta desde tiempos de la Carta Magna"; precisando que "el derecho a un proceso previo, legalmente tramitado, racional y justo, que la Constitución asegura a todas las personas, debe contemplar las siguientes garantías: la publicidad de los actos jurisdiccionales, el derecho a la acción, el oportuno conocimiento de ella por la parte contraria, el emplazamiento, adecuada defensa y asesoría con abogados, la producción libre de pruebas conforme a la ley, el examen y objeción de la evidencia rendida, la bilateralidad de la audiencia, la facultad de interponer recursos para revisar las sentencias dictadas por tribunales inferiores"(Rol 481, de 2006).

\section{Proyección}

Como puede apreciarse, la Carta Magna de Juan Sin Tierra incorpora un conjunto de disposiciones que ciertamente constituyen los antecedentes del Derecho Constitucional y, especialmente, de los derechos y libertades modernas. 
Las Constituciones precisamente surgen a partir del siglo XVIII como un límite al poder del monarca, por lo que su texto sirve de fuente de inspiración de las Declaraciones de Derecho de Estados Unidos y Francia, como igualmente de las más modernas, como la de Naciones Unidas, en 1948.

Del mismo modo, inician la idea de que la Ley Fundamental debe ser un Pacto entre los ciudadanos, quienes se expresan especialmente en el Congreso o Parlamento, Carta que debe ser cumplida por todos, sean gobernantes o gobernados.

Los derechos que reconoce y asegura siguen más vigentes que nunca, habiendo sido reiterados por siglos en diversas declaraciones y Constituciones, pudiendo reiterarse -entre otros- las libertades de movimiento y de comercio, la justa indemnización expropiatoria, la legalidad de los tributos, el derecho a un justo proceso, la proporcionalidad de las sanciones y la custodia de las garantías.

Indudablemente, la Carta Magna es la Carta de la Libertad, por ello en el memorial construido en Runnymede por la American Bar Association se le recuerda como "simbolo de la libertad bajo el derecho". 